\title{
ESTUDO DE COMUNIDADE E CONHECIMENTO CIENTÍFICO *
}

\author{
OCTAVIO IANNI \\ (Universidade de São Paulo)
}

No empenho de se conhecer, de maneira cada vez mais rigorosa e ampla, como ser social, o brasileiro das últimas décadas tem lançado mão das contribuições dos mais diversos grupos e escolas de cientistas sociais, dentre os quais se destacam os franceses, os alemães, os inglêses e os norteamericanos. As contínuas transformações verificadas ùltimamente na sociedade brasileira têm imposto à população problemas complexos, impelindo-a a interessar-se e desenvolver uma área da sua civilização que anteriormente se encontrava limitada às atividades de um pequeno grupo, conhecido como a "elite dos letrados". À medida que se tornam mais graves e intrincados os dilemas criados pelas mudanças radicais que se vêm verificando no seio da sociedade, cresce o interêsse pelas técnicas racionais de conhecimento e abandonam-se as doutrinas tradicionais, muitas vêzes meras representações ideológicas da mentalidade de grupos restritos. A lenta mas sistemática destruição da civilização agrária no Brasil, devida ao nascimento e à expansão do mundo urbano-industrial, tem provocado a elaboração de uma nova consciência histórica em grupos extensos da sociedade, da qual tendem a fazer parte essencial as categorias científicas criadas pelas ciências humanas. Daí a ênfase em estudos sôbre mudanças sociais, aculturação e assimilação, problemas educacionais, condições de mobilidade social, causas e efeitos das migrações, configurações de estruturas demográficàs, "ciclos" econômicos, subdesenvolvimento e crescimento econômicos, crises e conflitos políticos, alterações nas estruturas do poder, formação da estrutura societária de classes, destruição dos remanescentes da sociedade esçravocrata de castas, etc. E assim, ao mesmo tempo que se conhece, a sociedade brasileira incorpora e procura desenvolver paulatinamente os próprios instrumentos dêsse conhecimento, alcançando aos poucos um entendimento mais rigoroso e geral do homem, como criador e produto da sociedade. Emancipa-se, pois, dos complexos culturais tradicionais, que dominam ou limitam o seu funcionamento e al-

(*) Este trabalho foi apresentado à V Reunião Brasileira de Antropologia, realizada em junho de 1961, em Belo Horizonte. 
terações, ao impossibilitar a criação ou adoção de novas formas de pensar, agir e sentir.

Dentre as múltiplas influências dos estudiosos e escolas européias e americanas sôbre a formação das ciências sociais no Brasil, queremos examinar aqui uma contribuição particular, proveniente, em grande parte, dos centros norte-americanos. Ao lado das pesquisas sôbre relações raciais entre negros e brancos, as pesquisas sôbre comunidades rurais e urbanas talvez sejam a expressão mais clara das influências dos estudos sociais desenvolvidos nos Estados Unidos sôbre as investigações realizadas no Brasil. Evidentemente essa inspiração não é unilinear. Ao contrário, ela corresponde, ao mesmo tempo, às exigências do conhecimento científico de processos econômicos, culturais, sociais, ecológicos, etc. e, também, conforma-se a princípios positivistas que o pensamento social brasileiro já vinha incorporando, desde o século passado, no seu contacto com a França e a Inglaterra. Mais ainda, os estudos de comunidade, assim como outras formas monográficas de análise científica de fenômenos sociais, fazem parte do mesmo conjunto de contribuições que a sociedade brasileira tem incorporado, juntamente com a metodologia científica e o corpus teórico das ciências humanas. Em suma, o "estudo de comunidade" é um modêlo de investigação adotado pela maioria dos sociólogos e etnólogos brasileiros, desde os seus primeiros contactos com algumas das obras mais típicas das ciências sociais americanas ${ }^{1}$. Em parte, transferiu-se para o Brasil também o prestígio que cercava essa forma de investigação etno-sociológica. Dados alguns dos caracteres dêsse tipo de estudo de caso, êle passou a ser discutido nos cursos universitários e foi adotado nos projetos de pesquisa. Por exemplo, como recurso de estudo sistemático, êle permite a associação das pesquisas de reconstrução histórica e de campo, bem como a aplicação das técnicas de observação em massa e dos procedimentos qualitativos. Por isso o pensamento social brasileiro absorveu com certa facilidade essa forma de pesquisa, que já produziu mais de uma dezena de monografias no país ${ }^{2}$. No afã de libertar-se dos modelos tradicionais de reflexão sôbre a história social, encarados negativamente como para-científicos, nas novas instituições científicas optou-se pelo que parecia "mais científico". Para romper de maneira drástica com os ensaios históricosociais produzidos no passado, como se certos caracteres formais dessas obras devessem também ser sumàriamente abandonados com os métodos explicativos adotados, grande parte dos estudiosos formados pelas universidades e escolas criadas a partir de 1930 preferiu o que lhes foi apresentado como "científico", "positivo", "mais refinado". Desta maneira ganhou-se em precisão e rigor na observação e tratamento descritivo dos eventos, perdendo-se algumas vêzes a riqueza e a desenvoltura no uso criador da inteligência. Por isso, nem sempre o rigorismo das explanações positivistas pode ser encarado como contribuição real para um maior conhecimento da realidade histórico-social, nem um enriquecimento efetivo 
da ciência social no Brasil. Em parte, isto se deve ao fato de não se terem explorado devidamente as possibilidades abertas pelas monografias clássicas produzidas nos Estados Unidos.

Com essas considerações, ficam colocadas sob uma determinada perspectiva crítica as monografias sôbre comunidades brasileiras já publicadas por especialistas do país e de outras nacionalidades. E suas implicações se tornariam explícitas se nos dedicássemos à análise das próprias obras, examinando-lhes as hipóteses, as peculiaridades da reconstrução de fenômenos e processos, o encadeamento teórico dos componentes dos sistemas sociais, os tipos de explanações pretendidas e as alcançadas, a amplitude das generalizações formuladas, etc. Mas não pretendemos fazer esta discussão aqui. Por ora, pretendemos tão sòmente focalizar alguns temas gerais, que permitem a reflexão construtiva sôbre a situação e as perspectivas do estudo de comunidade no Brasil. Observe-se, pois, que não faremos um balanço das contribuições positivas de cada uma das obras. Em tôdas se encontram valiosas reconstruções empíricas, reflexões teóricas ou metodológicas, etc. O conhecimento científico da realidade sócio-cultural brasileira alcançado até o presente muito deve precisamente aos elementos reunidos por êsses estudos. Além disso, já foram realizados diversos balanços das múltiplas contribuições dos estudos de comunidade feitos no Brasil ${ }^{3}$. Sentimo-nos, por isso, à vontade para examinar seletivamente o assunto, orientando a discussão apenas para determinadas limitações das monografias publicadas e que parecem ilustrar as possibilidades atuais de progresso do pensamento científico no país.

Independentemente das ambições e das reais contribuições de cada uma das monografias (o que, como dissemos, não é objeto de nossas considerações aqui), um dos aspectos que mais atraem a atenção de quantos as examinam de uma perspectiva metodológica é o tipo de explanação efetivamente alcançado. Não há dúvida de quẹ em algumas mołografias o esquema teórico é rico, permitindo fecundas explorações das evidências selecionadas. Há estudos em que se observa a intenção de realizar uma análise mais ambiciosa, com generalizações destinadas a extravasar os limites estreitos da comunidade ou dos fenômenos reconstruídos. Mas essas aspirações não têm sido plenamente concretizadas, pelo simples fato da inadequação existente entre os alvos da investigação e os procedimentos metodológicos utilizados. Muitas vêzes a própria concepção do social, em sentido amplo, e das possibilidades do seu conhecimento, reduzem as perspectivas da explicação, fixando-a em segmentos do sistema econômicosocial e cultural, enfocados como unidades estanques ou com vinculações superficiais, exteriores, com as outras partes do todo. 
Essas intenções teóricas se tornam evidentes quando confrontamos os alvos da monografia, os tipos de dados observados e analisados e as generalizações pretendidas. A maneira pela qual é reconstruído o sistema econômico-social e cultural, o tipo de seleção dos pracessos considerados fundamentais, as conexões causais e funcionais atribuídas ou contestadas nas relações entre os fenômenos, o encadeamento verificado nas relações entre os eventos, os processos e a totalidade, todos êsses são aspectos das investigações efetuadas que revelam, a um tempo, os alvos empíricos e teóricos das monografias. Em Cunha, por exemplo, que é um estudo pioneiro no Brasil (deixando-se de lado o papel positivo que representa na formação e desenvolvimento do pensamento científico brasileiro), encontra-se o que, a nosso ver, é uma das limitações inerentes ao modêlo de pesquisa que estamos examinando. Apoiando-se principalmente no esquema teórico utilizado por Redfield em The Folk Culture of Yucatan ${ }^{4}$, Willems procurou descrever e explicar as mudanças sócio-culturais numa comunidade caipira do Vale do Paraíba, no Estado de São Paulo. "Não se trata - diz êle - de uma monografia no sentido um tanto vago da palavra. Não pretendemos abarcar tôdas as esferas da cultura 'caipira' de Cunha, mas sòmente aquelas em que o contraste entre tradição e transição se está tornando evidente. Um estudo pormenorizado dos aspectos tradicionais da cultura e organização social representa, por assim dizer, o 'pano de fundo' sôbre o qual se descortinam as mudanças que se fazem sentir com intensidade variável na vida da comunidade" ". Êsses são os alvos da investigação, cuja monografia se estende numa reconstrução empírica exaustiva, em que se descrevem a formação demográfica, a distribuição ecológica, as classes sociais, os grupos de vizinhança e mutirão, as relações entre os sexos e a estrutura da família, os diversos tipos de associações políticas, culturais, lúdicas, a organização e as transformações econômicas, as festas religiosas, as crenças e os ritos, a cultura ergológica; na segunda parte registram-se dados antropométricos da população local; e na terceira há notas sôbre objetos arqueológicos colhiłos na região. Como vemos, o simples enunciado dos principais temas tratados na obra revela uma discussão bem mais ampla do que seria necessário para a análise dos caracteres das mudanças sócio-culturais. O que se observa é uma reconstrução cuidadosa de múltiplos aspectos do sistema, sem que se explicitem as reais condições e tendências das mudanças constatadas. Quando, ao final, o autor ordena de par em par os fatôres responsáveis pela estabilidade e pela instabilidade da estrutura sócio-cultural ${ }^{6}$, não ficamos sabendo qual é o encadeamento dinâmico entre os fatôres ou as condições das transformações. Como já observou Florestan Fernandes, "as interpretações desenvolvidas param nos limites da caracterização empírica do funcionamento atual da estrutura social e da cultura" ${ }^{7}$. E' que o autor se decidiu por uma compreensão funcionalista da realidade cujos requisitos não the impunham avançar mais na explanação, descobrindo as conexões estruturais 
e funcionais diacrônicas que governam os fenômenos. Se examinássemos, um a um, cada um dos pares de "fatôres" responsáveis pela estabilidade e pela instabilidade do sistema econômico-social e cultural, observaríamos que as possibilidades de uma explanação mais ambiciosa permaneceram inexploradas. Mais ainda, todos os pares de fatôres ordenados poderiam ser reexplorados interpretativamente de diversas maneiras, em grupo, em pares reordenados e todos em conjunto. Mas para isso seria necessário lidar com uma outra concepção da realidade. Seria preciso abordar os fenômenos e processos tendo em vista uma concepção de totalidade que não admite nem um estado de equilíbrio nem uma distribuição harmônica das condições e fatôres, bem como das suas potencialidades dinâmicas. Caberia uma noção dos componentes do todo, tendo-se em vista as alternâncias hierarquizadas das condições, intensidades e tendências das mudanças, de conformidade com o modo de organização e produção da vida em sistemas econômicos de subsistência, de mercado e mistos, e segundo as conexões da comunidade com o sistema econômico-social inclusivo, capitalista, em expansão. Em suma, quando a análise se volta com exclusividade para a comunidade, como se através da inquirição intensiva, microscópica, fôsse possível descobrir todos os mecanismos fundamentais das transformações estruturais que a pesquisa pretenderia apanhar, ela não rcaliza a explanação completa. Muitas vêzes, e êste é o caso de alguns dos estudos publicados, o pesquisador pouco descobre, pois não se liberta da obsessão exclusiva de apanhar "fatos precisos", "rigorosamente obtidos". A preocupação em reconstruir os eventos nessas condições impedelhe apoiar as reflexões na compreensão de processos mais amplos, que se dão em tôda a região e, muitas vêzes, emergem com centros propulsores em outrós núcleos. Mas isto nos põe diante de outro problema.

E' comum o projeto de estudo sôbre comunidade enfrentar com dificuldades o problema da representatividade do núclec selecionado em face da região ou do país. Apesar de que geralmente se pretenda alto grau de generalidade para as formulações realizadas, nem sempre a unidade escolhida pode ser tomada como típica da área. Esta situação se deve principalmente a duas ordens de fatôres, que têm atuado no mesmo sentido, limitando o valor das interferências retidas nas monografias. Em primeiro lugar, em conseqüência da escassez de recursos materiais ou devido ao tipo de formação teórica que possuem, os pesquisadores não têm realizado uma sondagem preliminar na região, na base da qual deveriam fazer a escolha da comunidade melhor situada em face dos problemas levantados pelo projeto. Geralmente são condições extra-científicas que impõem determinada comunidade, o que limita bastante o alcance da análise. Em segundo lugar, não é fácil o exame científico dos problemas levantados por uma exploração inicial, que deve descobrir a unidade mais adequada ao estudo. Seria necessário que o pesquisador determinasse, antes, tendo em vista categorias teóricas prèviamente formuladas, quais seriam as va- 
riáveis, as condições e os fatôres que poderiam ser tomados como típicos do sistema econômico-social e cultural da área. Em outras palavras, êle deveria isolar, por meio da sondagem, os principais processos que estariam ocorrendo nas diversas comunidades, tendo em vista a independência relativa de uns em face dos outros e as determinações recíprocas. Dêste modo, seria possível uma decisão segura, relativamente ao núcleo melhor situado para a investigação, considerando os alvos teóricos e tendo em vista as possibilidades e limitações reais da unidade ${ }^{8}$.

Mas a questão não se restringe a êsses aspectos. O problema se torna ainda mais complexo e difícil quando a comunidade a ser escolhida deve apresentar-se num certo estágio de desorganização, tendo-se em mira os tipos de processos que se pretendam conhecer. Quando queremos descrever e explicar as transformações estruturais de um sistema que está sendo envolvido pelo capitalismo, como ocorre com algumas comunidades estudadas, é preciso que se esclareçam com precisão as condições empíricas e os critérios teóricos que cercam a seleção da unidade, se se quiser alcançar um conhecimento novo. São os processos a estudar que impõem a comunidade num período determinado do seu desenvolvimento.

Com frequiência, todavia, os projetos de estudo deixam por completo de lado considerações sôbre questões como essas. No meio brasileiro, os pesquisadores ainda não encontram motivações bastante fortes para explicar as condições teóricas e metodológicas que fundamentam as suas investigações. E essa situação, como não poderia deixar de ocorrer, acaba por produzir um empobrecimento das exigências dos próprios especialistas. Num caso concreto como o do estudo de comunidade, ao lado das limitações intrínsecas ao modêlo de pesquisa, não se pode menosprezar também o obstáculo representado pelo tipo de expectativa societária. Aliás, êste aspecto da questão se exprime com clareza quando examinamøs os elementos para "ação prática" oferecidos pelas monografias.

Um dos mais fortes impulsos para o desenvolvimento de estudos de comunidade no Brasil tem sido, exatamente, a intenção de oferecer aos administradores elementos seguros para os programas de educação, saúde pública, etc. Não se trata apenas de conhecer a realidade, mas sim de agir sôbre ela, ao menos nos setores que afetam diretamente as possibilidades de sobrevivência física das populações e o seu ajustamento produtivo às condições econômico-sociais e culturais emergentes. Como dizem Wagley, Azevedo e Costa Pinto, autores do projeto de estudos de três pares de comunidades no Estado da Bahia, "uma finalidade fundamental desta pequisa (conjunto de pesquisas) é fornecer uma base objetiva para o planejamento dos programas de educação e saúde pública nas zonas rurais do Estado" ${ }^{9}$. Como vemos, as expectativas de certos grupos sociais continuam a operar como um fator poderoso de desenvolvimento das pesquisas sociais. Os dilemas e tensões criados pelas modificações restritas ou globais dos sistemas econômico-ociais e culturais 
impelem as pessoas a apelar para as ciências humanas, na expectativa de que forneçam soluções imediatas. Diante do pauperismo, da doença, do analfabetismo, da crise da personalidade, da desorganização institucional - fenômenos êstes comuns em núcleos de economia de subsistência em fase de envolvimento pelo sistema capitalista de produção as autoridades apelam para os cientistas sociais, como se problemas como êsses caíssem fora do horizonte cognoscitivo dos homens, em suas atividades cotidianas, e as soluções fôssem ignoradas.

Não há dúvida, contudo, de que muitas vêzes é necessária a pesquisa, porquanto os fatôres responsáveis pelas manifestações de fenômenos indesejáveis são desconhecidos. Em certos casos, é preciso que a investigação descubra os mecanismos responsáveis pela emergência de tensões e problemas que afligem o indivíduo e os grupos, prejudicandolhes a adaptação produtiva ao meio e o ajustamento dinâmico à comunidade. Deixando-se de lado o caráter por natureza prático do conhecimento social, e as eventuais ações dos administradores, que podem orientar-se em múltiplas direções, mais ou menos conservadoras ou reformistas, resta considerar certos caracteres das expectativas dos próprios grupos atingidos pelos problemas. Mas não se trata apenas de discernir as manifestações do sistema sócio-cultural. E' preciso que se conheçam as suas tendências de modificação, as significações relativas dos seus elementos, as conexões da comunidade com a sociedade nacional, o sistema de dominação vigente e os seus suportes principais, as representações da consciência dos grupos e classes sociais, etc. para que as inovações sejam formuladas de maneira condizente com as condições e tendências reais do sistema. Referindo-se a um aspecto particular importante das expectativas societárias com relação à mudança sócio-cultural provocada, Oberg lembra o seguinte: "Um programa de desenvolvimentos comunitários formulado para ajudar a populaçạ̃o local a aumentar a sua produção agrícola e a melhorar as suas condições de saúde e educação, deveria ser planejado não apenas com base em dados objetivos, relativos a êsses setores, mas também com fundamento num conhecimento a respeito do que as próprias pessoas pensam e sentem acêrca da sua comunidade, dos seus problemas e da sua responsabilidade na resolução dêsses problemas. Além disso, é essencial conhecer em que áreas do Município a consciência da comunidade é mais desenvolvida - se na urbana ou rural, entre os homens ou as mulheres, entre os lavradores ou os não-lavradores, entre os mais instruídos, em comparação com os menos instruídos - e descobrir quais são as condições que fazem com que essas diferenças subsistam" ${ }^{10}$. E' necessário que conheçamos, pois, não só a configuração da estrutura econômico-social, mas também as condições culturais de absorção dos novos empreendimentos e técnicas. Em outros têrmos, qualquer programa de intervenção racional na realidade deve fundar-se no conhecimento das condições de possibilidades das ações dos homens, da praxis 
humana. E' preciso que se conheçam as formações culturais, vistas comc cristalizações que podem propiciar ou obstar a incorporação de outras formas de pensar, agir e sentir. Mesmo quando não se pretendam alterações estruturais, sòmente ao descobrir as leis que regem os complexos sócio-culturais e as suas conexões com a prática dos homens é que se oferece ao homem a liberdade de manifestar-se ou recriar-se.

Como vemos, dentre os problemas levantados pelas pesquisas de comunidades já efetuadas no Brasil, os aqui examinados refletem a natureza fundamental e as tendências principais das suas contribuições. Procuramos destacar principalmente: as preocupações teóricas, em especial aquelas ligadas à explanação descritiva encontrada nas obras publicadas; o problema da representatividade regional ou nacional das unidades selecionadas, tendo-se em vista os processos e fenômenos que se almejam conhecer; e as condiçốes teóricas da intervenção racional na realidade. Baseados nestas questões relevantes do conhecimento científico de fenômenos sociais, quisemos indicar alguns dos caracteres mais gerais dos estudos de comunidade publicados no país e, implìcitamente, as tendências de seus desenvolvimentos.

A despeito do caráter exploratório destas reflexões, acreditamos que elas põem em evidência alguns dos problemas que afetam positiva ou negativamente o desenvolvimento da pesquisa social no Brasil. Por um lado, é inegável que o estudo de comunidade, conforme foi posto em prática no país, é um modêlo de pesquisa que apresenta limitações graves. Trata-se de uma forma de tratamento científico de fenômenos e processos econômico-sociais, psico-sociais, culturais, etc. que não parece congruente com as exigências da reflexão científica mais ambiciosa. E' uma solução metodológica que tem sido confundida com um modêlo teórico de compreensão da realidade. Em consequiência da supervalorização dos procedimentos de pesquisa e da "fixação" de certas abordagens no desenvolvimento da etnologia e da sociologia, o estudo de comunidade assumiu um significado incompatível com a sua natureza: o que era uma solução metodológica se transformou numa alternativa teórica. De "unidade de observação para o estudo de uma cultura ou sociedade", de expressão local de um fenômeno ou problema social geral, de área para o teste de programas de intervenção racional na realidade ${ }^{11}$, o que lhe dá legitimidade como foco de investigação, em algumas monografias a comunidade é transformada num objeto em si, suscetível de propiciar, encarada isoladamente, um conhecimento significativo. Contìnuamente se perde de vista o fato de que êsse tipo de aglomerado humano é sòmente um entre vários focos de observação de fenômenos e processos cujas manifestações, condições de emergência e tendências devem ser conhecidas. Como uma das reações ao ensaísmo do período anterior a 1930, êsse tipo de investigação parece ter 
bloqueado as tendências mais criadoras da reflexão científica, em benefício de um rigorismo que muitas vêzes fica limitado apenas à observação e à reconstrução segmentária de fenômenos. Além disso, êstes estudos têm sido formulados com base em hipóteses que não nos parecem ricas de possibilidades teóricas, pois que preconizam quase sempre a classificação e a descrição. Alguns fenômenos contìnuamente examinados nesses estudos etno-sociológicos, tais como isolamento e contacto sócio-cultural, desorganização, individualização, mudanças sociais e culturais, etc. são encarados geralmente da mesma perspectiva, sem que se procure ultrapassar as limitações das focalizações clássicas do assunto. Não se nota qualquer tentativa de renovar a compreensão tradicional dêsses processos, descobrindo-lhes as dimensões que as primeiras investigações não conseguiram formular. Ao contrário, repetem-se as reconstruções descritivas, orientadas para as manifestações globalizadoras. Essa orientação se manifesta com clareza em determinadas obras, nas quais são descritas, uma a uma, as áreas tradicionais da investigação monográfica sôbre comunidades, sem que haja alvos teóricos ou sequer intenções integradoras. Nesses casos a obra se apresenta como um agregado de estudos de caso reunidos discricionàriamente num estudo de caso maior, como se verifica no enunciado dos títulos dos capítulos de um dêsses trabalhos: habitat, população, técnicas de subsistência, isolamento e contacto, linguagem, etiqueta, família, compadrio, ritos, cerimônias e crendices, comportamento político, relações raciais, conflito, solidariedade, humor, provérbios e ditos populares, mudança social, desorganização social. E' que nessa obra falta a preocupação explicativa que, necessàriamente, produziria a síntese dos componentes do universo econômico-social e cultural. A carência de hipóteses interpretativas em projetos como êsse impede o progresso da reflexão científica, inclusive no plano da simples reconstrução descritiva. Daí a dispersão de temas e problemas, repetidos da mesma maneira em diversas obras.

Por outro lado, e. em decorrência do que ficou dito no parágrafo anterior, o estudo de comunidade, com o qual se pretende uma compreensão globalizadora da realidade, tem abdicado sistemàticamente dêste alvo, limitando as possibilidades abertas pela pesquisa científica. As discussões de fenômenos tais como, por exemplo, as mudanças sociais e culturais, implicam uma apreensão global da realidade, devendo-se focalizar os níveis econômico-sociais, psico-sociais e culturais. Entretanto, nem sempre as obras abrangem essas áreas com o rigor e a compreensão necessários. Geralmente o sistema é fragmentado em partes autônomas, isoladas, vistas a priori como significativas, mas de maneira que o seu valor interpretativo fica prejudicado. Pouca importância tem a análise de componentes solitários da estrutura econômica, da estrutura social, do sistema cultural, da organização demográfica, etc., quando essas “áreas' da realidade não são vistas em sua concatenação dinâmica e numa hierarquização relevante do ponto de vista explicativo. O falso objetivismo de que se compenetrou certa corrente de 
cientistas sociais tem levado pesquisadores a eleger, de para em par, isolados, como se fôssem de significação semelhante, segmentos da realidade que são intrìnsecamente ligados, encadeados e hierarquizados .

Em síntese, os problemas levantados pelas monografias que serviram de base a esta contribuição podem ser agrupados da seguinte maneira. Em primeiro lugar, estão os relacionados aos próprios requisitos metodológicos dêsse tipo especial de estudo de caso, que impõe ao pesquisador um conjunto complicado de fenômenos e processos, cuja reconstrução e análise exigem um labor intelectual complexo e demorado. E, em segundo lugar, deve ser colocada a insuficiente adequação teórica e metodológica do pesquisador aos padrões do eștudo de comunidade. Aliás, êsses dois aspectos da questão se tornam evidentes quando lembramos que nem tôdas as possibilidades abertas pelas monografias norte-americanas foram exploradas no Brasil. Ao abandonar o padrão tradicional de reflexão especulativa sôbre fenômenos histórico-sociais, os estudiosos têm se mostrado satisfeitos com um modêlo de pesquisa científica que poderia ter aumentado bem mais o conhecimento da realidade social brasileira.

\section{NOTAS}

1) São particularmente as seguintes as monografias a que nos referimos: Middletown, A Study in American Culture, Robert S. Lynd and Helen M. Lynd, com prefácio de Clark Wissler, Harcourt Brace and Company, New York, 1929; The Folk Culture of Yucatan, Robert Redfield, The University of Chicago Press, Chicago, 1941; The Social Life of a Modern Community, W. Lloyd Warner and Paul S. Lunt, Yale University Press, New Haven, 1941.

2) Emílio Willems, Cunha, Tradição e Transição em uma Cultura Rural do Brasil, São Paulo, 1948; a mesma obra saiu em segunda edição sob o título Uma Vila Brasileira, Tradição e Transição, Difusão Européia do Livro, S. Paulo, 1961; Lucila Herrmann, Evolução da Estrutura Social de Guaratinguetá num Período de Trezentost Anos, Edição do Instituto de Administração, da Faculdade de Ciências Econômicas e Administrativas, U.S.P., São Paulo, 1948; Donald Pierson, Cruz das Almas, A Brazilian Village, United States Government Printing Office, Washington, 1951; Emílio Willems in cooperation with Gioconda Mussolini, Buzios Island, A Caiçara Community in Southern Brazil, J. J. Augustin Publisher, New York, 1952; Charles Wagley, Amazon Town, A Study of Man in the Tropics, The MacMillan Company, New York, 1953; a mesma obra foi publicada em tradução brasileira, por Clotilde da Silva Costa, sob - título Uma Comunidade Amazônica, Estudo do Homem nos Trópicos, Companhia Editôra Nacional, 1957; Fernando Altenfelder Silva, Análise Comparativa de Alguns Aspectos da Estrutura Social de duas Comunidades do Vale do São Francisco, Curitiba, 1955; Marvin Harris, Town and Country in Brazil, Columbia University Press, New York, 1956; Harry William Hutchinson, Village and Plantation Life in Northeastern Brazil, University of Washington Press, Seattle, 1957; Kalervo Oberg, Toledo, A Municipio on the Western Frontier of the State of Paraná, Rio de Janeiro, 1957; Kalervo Oberg, Chonin de Cima, A Rural Community in Minas Gerais, Rio de Janeiro, 1958; Aziz Simão e Frank Goldman, Itanhaém, Estudo sôbre o Desenvolvimento Econômico e Social de uma Comunidade Litorânea, edição da Faculdade de Filosofia, Ciências e Letras, U.S.P., São Paulo, 1958; H. D. Barruel de Lagenest, Marabá, Ci- 
dade do Diamante e da Castanha, Editôra Anhambi S. A., São Paulo, 1958; Alfonso Trujillo Ferrari, Potengi, Encruzilhada no Vale do São Francisco, Editôra Sociologia e Política, São Paulo, 1960; Esdras Borges Costa, Cerrado e Retiro: Cidade e Fazenda no Alto São Francisco, edição da Comissão do Vale do São Francisco, Rio de Janeiro, 1960.

Como se evidencia do que já foi dito, êste artigo não pretende examinar os problemas propostos pelos estudos sôbre comunidades indígenas.

3) Veja-se, por exemplo, Charles Wagley e Thales de Azevedo, "Sôbre métodos de campo no estudo de comunidade", Revista do Museu Paulista, Nova Série, volume V, São Paulo, 1961, págs. 227-237; Charles Wagley, "Estudos de Comunidades no Brasil sob Perspectiva Nacional", Sociologia, vol. XVI, n. ${ }^{\circ}$ 2, São Paulo, 1954, págs. 3-22; Antônio Cândido, "L'État Actuel et les Problèmes les plus Importants des Études sur les Sociétés Rurales du Brésil", Anais do XXXI Congresso Internacional de Americanistas, São Paulo, 1955, págs. 321-332; Gioconda Mussolini, "Persistência e Mudança em Sociedades de 'Folk' no Brasil", idem, págs. 333-335; Oracy Nogueira, "Os Estudos de Comunidades no Brasil", Revista de Antropologia, vol. III, n. ${ }^{\circ}$ 2, São Paulo, 1955, págs. 95-103; Florestan Fernandes, A Etnologia e a Sociologia no Brasil, Editôra Anhambi S. A., São Paulo, 1958, esp. págs. 17-78; 179-244.

4) Essa influência, que já é lembrada por Willems na primeira edição de sua obra, foi evidenciada completamente na introdução que escreveu para a segunda edição. Em suas palavras "a fim de analisar alguns dos efeitos que as inovações tiveram sôbre a estrutura social de Itaipava (Cunha), lancei mão de um conceito que, juntamente com o de desorganização e secularização, fôra usado por Robert Redfield nos seus estudos em Iucatã: individualização". (Cf. E. Willems, Uma Vila Brasileira, op. cì̀, pág. 12).

5) Cf. E. Willems, Cunha, op. cit., pág. 6.

6) Ibidem, págs. 168-169.

7) Cf. Florestan Fernandes, op. cit., pág. 48.

8) Abstemo-nos de particularizar estas considerações, porquanto discutimos a questão em outro artigo. (Cf. Octavio Ianni, "O Método em 'Uma Comunidade Amazônica”", Sociologia, vol. XX, n. ${ }^{\circ}$ 4, São Paulo, 1958, págs. 574-580).

9) Cf. Charles Wagley, Thales de Azevedo e Luís A. Costa Pinto, Uma Pesquisa Súbre a Vida Social no Estado da Bahia, Com texto em inglês, Publicações do Museu do Estado, n. ${ }^{0}$ 11, Bahia, 1950, pág. 7 ; também págs. 9 e 20. Outros elementos sôbre os alvos "práticos" de alguns estudos de comunidade levados a efeito no Brasil encontram-se em: Charles Wagley, Amazon Town, op. cit., esp. págs. VII-XI, 1--19 e 257-295; Kalervo Oberg, Chonin de Cima, op. cit., esp. págs. 137-146.

10) Cf. Kalervo Oberg, Toledo, op. cit., pág. 76.

11) Cf. Conrad M. Arensberg, "The Community as Object and as Sample", American Anthropologist, Volume 63, Number 2, Part 1, Menasha, Wisconsin, 1961, págs. 241-264; citação extraída da pág. 241. 